\title{
Research on the New English Language Teaching Approach based on Sharing of the Knowledge Economy under the MOOCs Background
}

\author{
Fei Ma \\ Foreign Language Department, \\ The Engineering\&Technical College of Chengdu University of Technology, Leshan, \\ Sichuan Province,614000
}

\begin{abstract}
In this paper, we conduct research on the new English language teaching approach based on sharing of the knowledge economy under the MOOC background. College English teaching is the core part of education in colleges and universities that are leading an indicator of college teaching can reveal most times the imprinting to teaching in colleges and universities. College English teaching from scratch, since the childhood, beyond the difficulty of the teaching area, through the teaching of confusion, but always insist on teaching idea of development as the center, continuously innovative fusion of gesture to the new development of English teaching to maximize the realization of the value of English teaching and cultivate highly qualified English talents for the society. Our research uses the MOOC platform to optimize the traditional education pattern which is innovative.
\end{abstract}

Keywords- MOOC Background, English Language, Knowledge Economy, Sharing Approach.

\section{Introduction}

In recent 10 years the Internet a revolutionary impact on many industries, Internet companies rise one after another, many traditional industry by the huge impact, but as an important part of economic and social education compared with other industries is not affected by the Internet too much, but the information technology is beginning to change the last one hundred years of college education mode. Higher education industry chain is based on knowledge chain. Lasts one hundred years of traditional university education monopoly on knowledge production, dissemination and consumption of each link, as knowledge students receiving object, we need to pay a high tuition to learn the knowledge in university and the emergence of the MOOCs changes the education status and influence the mode.

According to the literature survey, the characteristics of the MOOC could be summarized as listed aspects. (1) MOOC contributes to saving the cost of education and realizes the education fair. The rise of MOOC makes more and more people can accept higher education quality. Is a kind of interactive open mode of online learning, to make different populations around the world to share high quality education resources, the passage of a massive open online courses, more and more universities have to anyone who want to learn the individual opened the door of learning, especially for students from rural can obtain the equal opportunities to learn through online resources. (2) The fragmentation of the curriculum organization form. The pieces of a single content repeatedly for rendering to organization form of skilled can effectively improve the absorption of knowledge, in addition, the fragmentation of curriculum organization also need to conform to the time, every time learning time is not long, but also can learn anytime and anywhere. (3) Flexible ways of evaluation. MOOC learners mutual system is developed, the teacher according to the course content arrangement of the tasks and task evaluation standard, within the prescribed time to complete the learning task and submit, in the form of peer mutual between learners in the strict accordance with the evaluation standard to make evaluation, and give advice, to supervise and urge learners to complete assignments on time, at the same time through mutual can also promote the mutual learning efficiency [1-2]. 
For language learning, both Chinese and English, we usually adopt the mode of learning are stored knowledge and memory, and then through the imitation and the practice use, into their own language ability. In college English teaching, to cultivate students' comprehensive English ability, to increase the students' English level to a new stage, there must be the guidance of the linguistic theories. English linguistics theory is a scientific theory foundation which can guide teachers according to the rule and character of the English language, taking reasonable and effective method to implement the teaching, to help students with English language used in practice, finally internalized as their own ability.

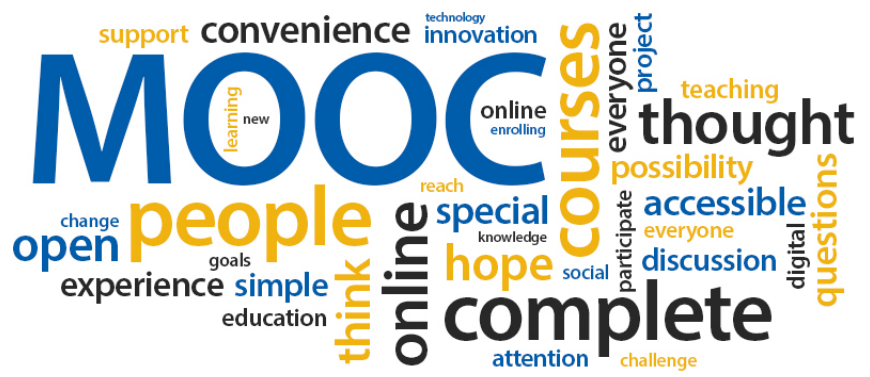

Figure 1. The Keywords of the MOOC Education Paradigm

In this paper, we conduct research on the new English language teaching approach based on sharing of the knowledge economy under the MOOC background. Linguistics teaching evaluation should adhere to the student for this based on ability, comprehensive examination and thoughtful, scientific and technical unification, correct play a guiding role of the exam, do to arouse and cultivate students' interest in study, establish a sense of accomplishment and self-confidence to improve comprehensive language using ability. In the following sections, we will discuss in detail.

\section{Our Proposed Methodology}

The Characteristics of MOOC. With the rapid development of information technology and network technology, a large number of network education resources have sprung up, which laid the foundation for the development of online education. Learning scientific studies show that the network education quality is affected by the quality of education resources, not only more decided by learners' learning activities. Learning activity design and research gradually become a hotspot in research of network education in recent years. Activity theory emphasizes the learner centered, the learners' learning as a learning activity of the subject to object. MOOC's appear making tens of thousands of learners around the world gathered together, in order to the common learning goals of mutually cooperative learning. MOOC is a new form of open courses, with the future, the prevalence of the personalized learning, lifelong learning based on MOOC learning will be developed rapidly. Besides the analysis on MOOC, the reason for causing the appearance of MOOC can be summarized as follows.

- The progress of Internet technology. Before the network technology and the popularization of broadband for audio-visual education resources can be more convenient to get, a wide range of the development of the social network for were used by learners of the geographical space between brought a better platform for communication and discussion, which greatly reduces the threshold of online learning [3-4].

- The lag of traditional education mode a pandemic. Traditional education model for analysis of students thinking ability, deductive inference ability, system thinking ability and the reception ability of knowledge training has a great and irreplaceable role. But its drawback is ignored the students' initiative, initiative and the independence.

- The needs of the vocational education in the future. In the future, the vocational education will become even more important, both for the students and country. While the MOOC for the 
development of the vocational education provides a great tool. In today's knowledge and the information update speed is faster and faster, the shelf life of knowledge, and even some of the technology are reduced.

MOOC is the essence of network course and traditional network curriculum's biggest difference is that MOOC provides the complete teaching model can give learners, providing can participate in the online course of study, anywhere, anytime and at the same time for the network course of learners to provide tens of thousands of potential partners, it promoted the development of lifelong learning and the equal education. Through the interaction between the learner and can not only for the students to solve the problems in the study can also provide learners with more new learning content. Therefore, in the process of MOOC course, learners can learn around the established goals, adopt a variety of the ways such as active learning, inquiry learning to develop learning activities.

The Sharing of the Knowledge Economy. More and more personal consumption entity be shared, a kind of "shared economy" is becoming the trend of the mainstream of the society one of the industry pattern and "sharing economic" this new business trend in the increasingly mature at the same time, also has given rise to more than thousands of the emerging enterprises, with the new genes of these enterprise achievement in its own at the same time, it also provide a new value orientation for the development of the society and the figure two illustrates this feature [5].

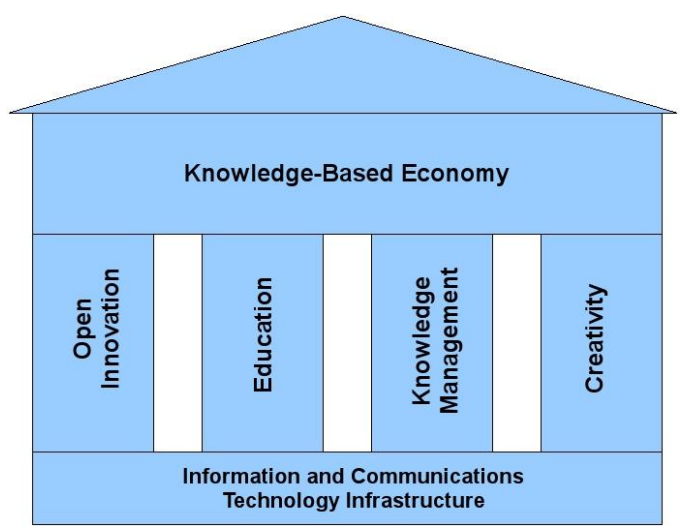

Figure 2. The Architecture of the Knowledge Economy

People as the original creator of social wealth and eventually person, have a duty to actively seek the way of economic and ecological development that must take the rule of law regulating the market the competition behavior of economic subject and bounded rationality of individual and the collective irrational contradictions. Individual behavior not only involves the private costs and benefits, and is likely to cause other market players are forced to bear the additional cost or increase revenue, in such a situation, the collective irrational trend is bound to strengthen competition, also produce the Pareto improvement space, namely the need of individual activities the externality of incentive, in brief, the purpose of incentive is the individual behavior of the internalization of the externality, forced through rules, forced to produce externalities of individual social costs and social benefits can be converted to the private costs and private benefits to make the behavior main body to assume full responsibility for their actions, and by individual optimal choice for social optimal.

The Development Trend of English Education. In the language teaching teachers should pay attention to the professor of the cultural background knowledge. Language is the carrier of culture, different culture that has produced different kinds of language, so teachers in the teaching process combined with the cultural background knowledge to teach 
language is particularly important. As an English language teaching, teachers should not only skillfully master the language, but also deeply understand the cultural background of the language, in order to better use the language to students. Under the guidance of students in teacher culture import, to improves the sensitivity to the culture, to enhance the enthusiasm of learning a foreign language, and, in turn, to understand the structure of language with a more in-depth study room for language and is using the language.

Learning another foreign language is to cultivate an important way of the target language culture consciousness. Language is not only a sound symbols used for the human communication arbitrary system, but also a carrier of culture, it to performance and the cultural inheritance. Language is the reflection of culture it reflects culture and is influenced by culture and restriction. Therefore, learning a language, not only in learning phonetics, grammar, vocabulary and idioms of level, to know more about the culture and the native speakers of the language belongs to the people how to treat people, and how to use language to express their thoughts [6-7].

Based on the literature review, the optimal and revised approaches for future English education ways could be summarized as the follows. (1) Introduction of allusions or saying. Existing in many teaching materials will refer to some allusions, proverbs, or the story in the bible, or Greek myths and legends. This not only enhances the teaching material's story, and also more convenient to transfer the ideas of the author, it is easier to inspire the readers' interest. (2) Reasonable use of multimedia. The use of multimedia is beneficial to students more intuitive understanding of the teaching content, so it will be easier to inspire students' interest in learning. Therefore, in classroom teaching, teachers can reasonable use of multimedia, can take advantage of the multimedia visual and vivid to introduce the students to the differences between Chinese and western culture. (3) Help the students from ignorant to mature. Semantic culture refers to the culture associated with semantics, or refers to the semantic system of a language contained in the cultural content or reflected by the cultural spirit. Language construct culture refers to culture associated with the language structure, namely language, phrases, sentences and discourse and reflects the cultural characteristics of the discourse structure. Pragmatic cultural meaning is related to the pragmatic culture, or refers to the cultural conventions of use.

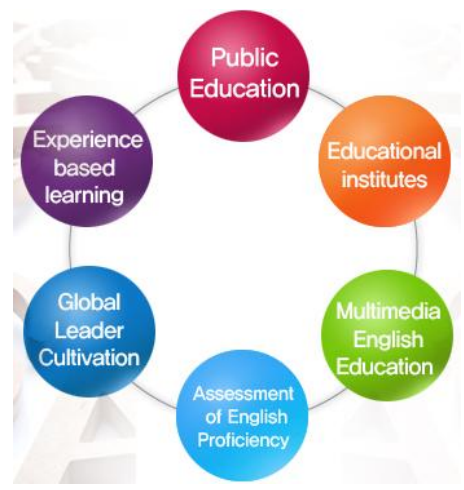

Figure 3. The Future of the English Eucation

The English Linguistics. Linguistics set purpose mainly is to promote students to understand the main achievements of human civilization development, and realize the language for social, economic, and the important role of the personal accomplishment. Teachers in the process of teaching to the teaching contents, teaching methods and teaching evaluation in-depth research, which will be those that can cultivate students' thinking ability teaching methods used in practical teaching [8].

English linguistics can improve students' language thinking ability, so as to promote improvement of English language and literacy, therefore, should be dominant in the curriculum design. However, relative to the language of the practical application, the actual linguistic theories is relatively abstract; How to coordinate the relationship between the two, applied English linguistics theory in the practice of the specific English learning and the teaching of the top 
priority in the actual teaching. Due to its abstractness, as make it hard for students to understand, the difference of knowledge and experience of differences can also lead to students' understanding of linguistics. Positioning of college English linguistics is to cultivate students thinking ability, have a certain width of linguistics can help students to broaden the thinking, enrich the students' way of thinking, improve the ability of solving practical problems. With the assistance of English linguistics, the education should focus more on the listed aspects. (1) Cultivate students' logical thinking ability. Logical thinking ability to not only plays an important role in English learning, learning is also important for other discipline. It mainly refers to the concept of thinking, in the language as the carrier, the main characteristics is abstract. (2) Develop the students' ability of the associative thinking. Idea is to point to in all-round multi-angle research problem, to seek a variety of the ways to explore the problems, to seek answers to the questions from different aspects of thinking method. Student association is wider, the stronger the ability to manage knowledge, thus widen the students' thinking of extensity, strengthened the pertinence of thinking, to improve the students' ability of reasoning and thought.

\section{Conclusion}

In this paper, we conduct research on the new English language teaching approach based on sharing of the knowledge economy under the MOOC background. There is no doubt that the rise of MOOC, give the impact of the traditional university is huge. A person, no matter who, through a computer or other internet-enabled devices, network, can learning and teaching, and can learn together with people all over the world, by learning to link together the people all over the world, this is the last people hard to imagine and MOOC impact on higher education is twofold, both opportunities and challenges. In the future, we will review more paper on the MOOC and the corresponding applications on the English education to enhance the performance of the current teaching mode.

\section{References}

[1] Skerrett, Allison, Alina Adonyi Pruitt, and Amber S. Warrington. "Racial and related forms of specialist knowledge on English education blogs." English Education 47.4 (2015): 314.

[2] Wachter, Bernd. "Teaching in English on the rise in European higher education." International higher education 52 (2015).

[3] Rezaei, Saeed. "Maryam Borjian: English in post-revolutionary Iran: From indigenization to internationalization." Multilingua 34.3 (2015): 439-442.

[4] Rish, Ryan M., and Audra Slocum. "Video-mediated teacher inquiry with pre-service English teachers." Video reflection in literacy teacher education and development: Lessons from research and practice. Emerald Group Publishing Limited, 2015. 211-233.

[5] Li, Yanxiong. "Analysis on Learning Behavior of English Learners on Basis of Data Mining Technology." 2015 International Conference on Education Technology, Management and Humanities Science (ETMHS 2015). Atlantis Press, 2015.

[6] Das, Amit Kumar, Anamika Das, and Soumit Das. "Present Status of Massive Open Online Course (MOOC) initiatives for Open Education Systems in India-An Analytical Study." Asian Journal of Multidisciplinary Studies 3.7 (2015).

[7] Banister, Savilla, Rachel Reinhart, and Cindy Ross. "Designing an Effective Massive Open Online Course for Educators: Evidence from Student Experience." Society for Information Technology \& Teacher Education International Conference. Vol. 2015. No. 1. 2015.

[8] Wagner, Rosana, et al. "MOOCs of Inclusive Technology in Teacher Education for Vocational Education." Creative Education 6.17 (2015): 1832. 